\title{
Chalcopyrite Leaching in Acidic Chloride Solution without Sulphates
}

\author{
Eduardo Luis Recalde Chiluiza ${ }^{1,2 *}$ and Patricio Navarro Donoso ${ }^{1}$ \\ 1 Universidad de Santiago de Chile, Department of Metallurgical Engineering, Av. Bernardo O'Higgins 3363, Santiago, Chile. \\ 2 Escuela Superior Politécnica del Litoral, ESPOL, Facultad de Ingeniería en Ciencias de la Tierra, Campus Gustavo Galindo \\ Km 30.5 Vía Perimetral, P.O. Box 09-01-5863, Guayaquil, Ecuador \\ * Corresponding author: erecalde@espol.edu.ec
}

Received July 7, 2016; Accepted November 29, 2016.

\begin{abstract}
Chalcopyrite leaching in acidic chloride solution without sulphates. The effect of dissolved oxygen and ferrous/ferric/cupric ions in solution on the leaching behavior of chalcopyrite and the phenomenology of the passivating layer formation on the chalcopyrite surface in an aqueous acidic chlorinated medium with dissolved oxygen and without sulphate are studied. The research was performed using pure chalcopyrite samples with particle sizes of +45 to -75 microns $(-200+325$ mesh). It was found that the formation of hydrogen sulfide $\left(\mathrm{H}_{2} \mathrm{~S}\right)$ at room temperature and atmospheric pressure is a possible precursor of passivating species that prevent chalcopyrite dissolution.

Keywords: Chalcopyrite; Chloride; Ferrous; Leaching; Passivation.
\end{abstract}

\section{Introduction}

Most of the world's copper production has been obtained from secondary sulfides, which can be oxidized, as well as from other mixed sulfides. However, the exploitation of these sulfides during centuries has led to their scarcity, leaving as an alternative the most abundant copper sulfide in nature, but also the most refractory in leaching processes: chalcopyrite, [1-4].

Hydrometallurgical technology offers the possibility of economically processing some refractory mineral species, [5]. Processes involving chlorides have been of great interest because of their ability to increase the leaching kinetics in acid media at atmospheric pressure, [6,7]. The mechanism of chalcopyrite leaching is an issue currently under debate; however, since much of the research has been carried out under different experimental conditions, it not always comparable, [8-11].

Third, [12], reported that in acidic sulphate solutions, in the voltage range of 450 to $650 \mathrm{mV} / \mathrm{SHE}$, there is an increase of the leaching rates with dissolved iron ions. This low voltage effect is attributed to the release of ferrous ions, which increase the extraction rate of copper from chalcopyrite above a critical voltage (greater than $500 \mathrm{mV} / \mathrm{SHE}$ ); below that voltage, the extraction rate drops. The results show that the kinetics of chalcopyrite leaching increases in ferrous sulphate solutions with dissolved oxygen, and diminishes in aerated solutions of ferric sulphate, [13], where the amount of copper recovered with 0.1 $\mathrm{M}$ ferrous sulphate $(\mathrm{pH} 1)$ is five times greater than that obtained with ferric sulphate.
Resumen: Lixiviación de calcopirita en soluciones ácidas cloruradas sin sulfatos. Se estudia el efecto del oxígeno disuelto y de iones ferrosos/férricos/cúpricos en solución en la lixiviación de la calcopirita y la fenomenología de formación de una capa pasivante sobre la superficie del mineral de calcopirita, en un medio acuoso de ácido clorhídrico con oxígeno disuelto y sin sulfatos. El trabajo experimental se realizó con muestras de calcopirita pura con granulometría entre +45 a $-75 \mu \mathrm{m}$, (malla $-200+325$ ). Los resultados demuestran la formación de sulfuro de hidrógeno $\left(\mathrm{H}_{2} \mathrm{~S}\right)$, a temperatura ambiente y presión atmosférica, siendo el posible precursor de especies pasivantes de la disolución del mineral de calcopirita.

Palabras clave: Calcopirita; Cloruro; Ferroso; Lixiviación; Pasivación.

The objective of the present research is to contribute new knowledge on copper leaching from chalcopyrite ore, in a chlorinated acid medium without sulphate, under weakly oxidizing conditions, with the coexistence of ferrous/cupric ions. Given that the precursors of the passivating layer and its formation, in the absence of sulphates, have not been previously established, this will be investigated under ambient conditions.

\section{Experimental}

The ore used corresponds to a massive chalcopyrite from $\mathrm{Du}$ rango, Mexico. The ore was crushed in an agate mortar, in order to avoid sample contamination. The ore was then classified granulometrically and the particle size range selected for in the present study was +45 to -75 microns $(-200+325$ mesh $)$. The mineralogical composition of this size fraction was determined by X-ray fluorescence (Siemens ${ }^{\circledR}$ SRS-3000 Sequential X-Ray Spectrometer), X-ray diffraction (Siemens ${ }^{\circledR}$ D5000 X-ray diffractometer) and SEM micrograph (TESCAN ${ }^{\circledR}$, model Vega-3, electron-scanning microscope).

The solutions were prepared with double distilled water and analytical reagent grade chemicals (Merck $\left.{ }^{\circledR}\right)$ : sodium chloride, ferric chloride, potassium chloride, cupric chloride, ferrous chloride, etc. The $\mathrm{pH}$ was adjusted by adding concentrated hydrochloric acid. Iron and copper ions were added as chlorides and $1 \mathrm{M} \mathrm{Na}^{+}$as $\mathrm{NaCl}$. The additional amount of chlo-

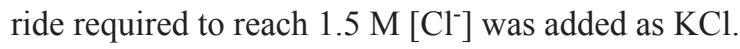


To determine the effect of dissolved oxygen and its participation in the reactions that take place on the surface of the chalcopyrite, tests were performed in solutions with and without dissolved oxygen. Aerobic tests were carried out by introducing oxygen into the system to maintain a dissolved oxygen concentration of $8 \mathrm{ppm}$. For the tests without dissolved oxygen, an inert gas (nitrogen) was bubbled previously into the solutions to remove the majority of dissolved oxygen and lower its residual concentration to less than $1 \mathrm{ppm}$.

The experimental conditions that varied were dissolved oxygen concentration (for test sets with and without dissolved oxygen), the $\mathrm{Fe}^{2+}$ and $\mathrm{Fe}^{3+}$ concentrations (0, 0.025 and 0.05 $\mathrm{M})$ and the $\mathrm{Cu}^{2+}$ concentration $(0$ and $0.01 \mathrm{M})$. The potassium ion concentration varied according to the stoichiometric requirements to reach $1.5 \mathrm{M} \mathrm{Cl}^{-}$and $1 \mathrm{M} \mathrm{Na}^{+}$). Table I shows the experimental leaching conditions for the tests with and without dissolved oxygen, for the different combinations of initial ferrous/ferric/cupric ions. The parameters that remained constant during the tests were leaching time $(400 \mathrm{~h}), \mathrm{pH}(1)$, chlorine concentration $(1.5 \mathrm{M}), \mathrm{Na}^{+}$concentration $(1 \mathrm{M})$, solution volume $(100 \mathrm{~mL})$ and chalcopyrite ore leached $(0.5 \mathrm{~g})$.

In addition to these tests, a preliminary test 1-O2N2 (molar concentrations: $\mathrm{Fe}^{2+} 0.50 / \mathrm{Cu}^{2+} 0.01 / \mathrm{Cl}^{-} 1.5 \mathrm{M}$ at $\mathrm{pH}$ 1) was carried out, leaching during for $400 \mathrm{~h}$ in an aqueous solution with dissolved oxygen, after which the reactor was hermetically sealed so that no more oxygen could enter the system. The purpose to initially have oxygen in the solution was to initiate the $\mathrm{H}_{2} \mathrm{~S}$ generating reactions. The reactor was later hermetically sealed to prevent the $\mathrm{H}_{2} \mathrm{~S}$ produced from escaping, allowing it to act as a precursor for the passivating species on the chalcopyrite surface.

The residue from each leaching test was recovered from the aqueous system by vacuum filtration, using a $0.2 \mu \mathrm{m}$ micro filter that retained the solid residues; these were washed with abundant water acidified to $\mathrm{pH} 1.6$ to recover the solids adhered to the reactor walls and to avoid the precipitation of iron hydroxides. The residues were analyzed by SEM and X-ray fluorescence.

\subsection{Experimental methodology}

A volume of $100 \mathrm{~mL}$ of solution and $0.5 \mathrm{~g}$ of chalcopyrite were combined in a glass reactor, adjusting to $\mathrm{pH} 1$ with concentrated hydrochloric acid. The slurry was placed in an orbital mechanical stirrer at $215 \mathrm{rpm}\left(\mathrm{LabTech}^{\circledR}\right.$ shaking incubator model LSI-3016R) during $400 \mathrm{~h}$ at room temperature. The reactors were used for both the aerobic and anaerobic tests. In the anaerobic experiments, a screw cap, hermetically closed with parafilm, was employed to avoid the access of oxygen into the system. In the tests with dissolved oxygen, the same reactors were used, but with a cap that allowed oxygen introduction into the solution, diverting the exit flow of air into a flask containing silver nitrate (indirect method to qualitatively determine the formation of hydrogen sulfide, see Fig. 2). Of the total $\mathrm{H}_{2} \mathrm{~S}$ formed during the acid leaching of chalcopyrite, only a part was carried into the silver nitrate solution by the injected air, some of which was lost to the atmosphere; the rest stayed in the leaching solution. For this reason, the experimental set-up and the results obtained are only intended to confirm $\mathrm{H}_{2} \mathrm{~S}$ generation, not to quantify its production.

It is known that the rate of dissolution in chlorinated or sulphated solutions does not increase with the stirring velocity, [14], because the rate of dissolution is not controlled by the mass transfer in the solution, especially considering the lengthy experimental times. Therefore, agitation does not need to be excessive, rather just sufficient to ensure that the ore does not become agglomerated and the particles remain suspended. This guarantees that the mixture remains homogeneous over the entire leaching reactor, [15]. To avoid the solution loss due to sampling, the volumes removed ( $3 \mathrm{~mL}$ aliquots) were replaced by the same volume of solution of the same initial concentration, [16]. The total volume of solution was monitored and maintained constant with double distilled water to compensate for loss by evaporation.

Samples were taken every $100 \mathrm{~h}$ for chemical analysis, keeping the temperature in the range of 25 to $30^{\circ} \mathrm{C}$. The analysis of total copper and iron in the aqueous samples was made by atomic absorption spectrometry (GBC Scientific ${ }^{\circledR}$ model SensAA). The concentration of ferrous ions was determined by the phenanthroline spectrophotometric method (Rayleigh ${ }^{\circledR}$ model UV1601 UV/VIS spectrophotometer), [17].

\section{Results and discussion}

\subsection{Results}

Table I and Fig. 1 show the different experimental conditions and the results of the tests made on the solutions, with

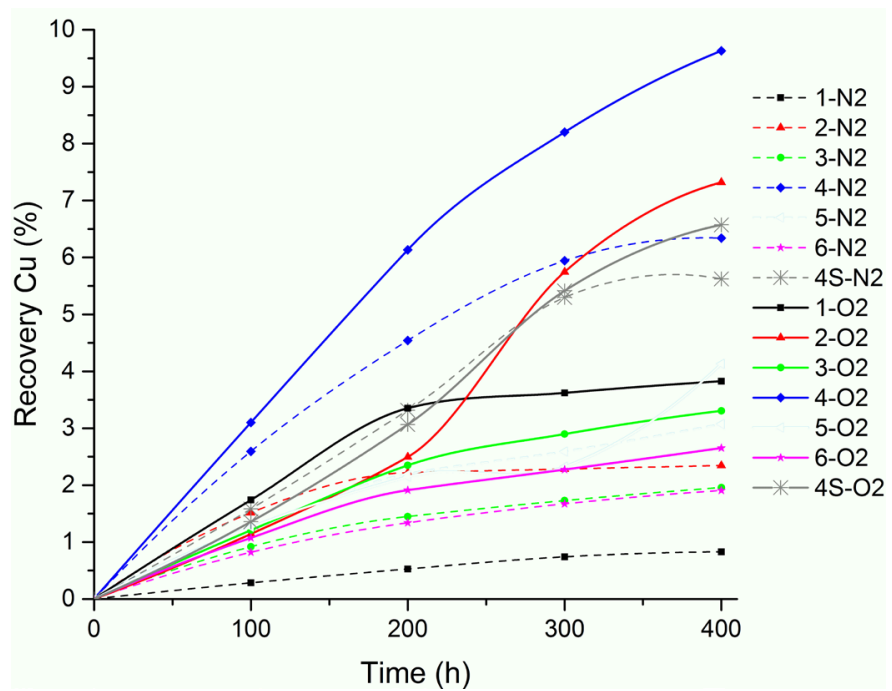

Fig. 1. Copper extraction curves during $400 \mathrm{~h}$ of leaching for all the tests, under aerobic $\left(\mathrm{O}_{2}\right)$ and anaerobic $\left(\mathrm{N}_{2}\right)$ conditions, $1.5 \mathrm{M} \mathrm{Cl}^{-} ; 1 \mathrm{M}$ $\mathrm{Na}^{+} ; \mathrm{pH} \mathrm{1}$; acidified with concentrated hydrochloric acid, volume of $100 \mathrm{~mL}$ of solution and $0.5 \mathrm{~g}$ of chalcopyrite, orbital mechanical stirrer at $215 \mathrm{rpm}$ at room temperature. 
Table I: Experimental conditions with 400 h of leaching. N2: tests without dissolved oxygen; O2: dissolved oxygen tests, $1.5 \mathrm{M} \mathrm{Cl}^{-} ; 1 \mathrm{M} \mathrm{Na}^{+}$; $\mathrm{pH} 1$; acidified with concentrated hydrochloric acid, and analytical results of leaching residue (1-O2N2 with initial dissolved oxygen)

\begin{tabular}{|c|c|c|c|c|c|c|}
\hline \multirow[b]{2}{*}{ Test } & \multicolumn{3}{|c|}{ Concentration (M) } & \multirow[b]{2}{*}{ Conditions } & \multirow{2}{*}{$\begin{array}{c}\text { Cu extraction } \\
(\%)\end{array}$} & \multirow{2}{*}{$\begin{array}{c}\text { Average potential } \\
(\mathrm{mV} / \mathrm{SHE})\end{array}$} \\
\hline & $\mathrm{Fe}^{3+}$ & $\mathrm{Fe}^{2+}$ & $\mathrm{Cu}^{2+}$ & & & \\
\hline $1-\mathrm{N} 2$ & 0.05 & & & Chlorides & $0.83 \%$ & 564 \\
\hline $3-\mathrm{N} 2$ & & 0.05 & & & $1.96 \%$ & 562 \\
\hline $4-\mathrm{N} 2$ & & 0.05 & 0.01 & & $6.34 \%$ & 563 \\
\hline $6-\mathrm{N} 2$ & 0.025 & 0.025 & & & $1.91 \%$ & 562 \\
\hline $4 \mathrm{~S}-\mathrm{N} 2$ & & 0.05 & 0.01 & Sulphates & $5.62 \%$ & 562 \\
\hline 1-O2 & 0.05 & & & Chlorides & $3.83 \%$ & 553 \\
\hline 2-O2 & 0.05 & & 0.01 & & $7.32 \%$ & 550 \\
\hline 3-O2 & & 0.05 & & & $3.31 \%$ & 568 \\
\hline 4S-O2 & & 0.05 & 0.01 & Sulphates & $6.57 \%$ & 567 \\
\hline $1-02 N 2$ & & 0.50 & 0.01 & Chlorides & $0.84 \%$ & 518 \\
\hline
\end{tabular}

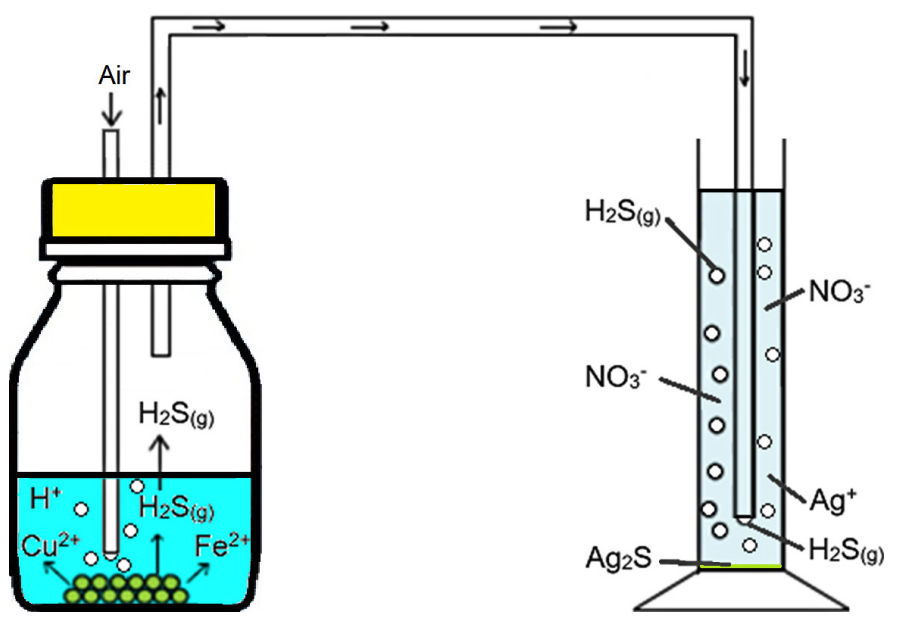

Fig. 2: Indirect determination of $\mathrm{H}_{2} \mathrm{~S}$ formed during the leaching of chalcopyrite, [18].

and without dissolved oxygen, after $400 \mathrm{~h}$ of leaching. The tests without dissolved oxygen are from 1-N2 to 6-N2, without added sulphates, at $\mathrm{pH} 1$, constant $1 \mathrm{M}$ sodium and $1.5 \mathrm{M}$ chloride concentrations; test $4 \mathrm{~S}-\mathrm{N} 2$ was performed under the same above conditions, but with the addition of iron and copper ions as sulphates. The tests with dissolved oxygen are from 1-O2 to 6-O2, without added sulphates, at $\mathrm{pH} 1$, constant $1 \mathrm{M} \mathrm{Na}^{+}$and $1.5 \mathrm{M}$ chloride concentrations; test $4 \mathrm{~S}-\mathrm{O} 2$ was performed under the same above conditions, but with the addition of iron and copper ions as sulphates.

In the tests with dissolved oxygen, the analysis of the precipitate formed by the reaction of silver nitrate with the $\mathrm{H}_{2} \mathrm{~S}$ coming from the reactor showed that it was the same in all tests. Fig. 3 show test with SEM micrograph of the sediments from the silver nitrate solution of test with oxygen, that there is evidence for the formation of $\mathrm{Ag}_{2} \mathrm{~S}_{(\mathrm{s})}$ in all tests, but cannot be quantified due to the co-precipitation of $\mathrm{AgCl}_{(\mathrm{s})}$ caused by the entrainment of $\mathrm{HCl}_{(\mathrm{v})}$ and its introduction to the flask.

A series of preliminary tests were performed using the hermetically capped leaching reactors, containing ambient oxygen, where no additional oxygen was introduced. Fig. 4 shows the SEM micrograph and X-ray diffraction of the altered chalcopyrite leaching residue from the test with a large quantity of ferrous ion $\left(1-\mathrm{O} 2 \mathrm{~N} 2\right.$, molar concentrations: $0.50 \mathrm{Fe}^{2+} / 0.01$ $\left.\mathrm{Cu}^{2+} / 1.5 \mathrm{Cl}^{-}\right)$at $\mathrm{pH} 1$, after $400 \mathrm{~h}$ of leaching.

Fig. 5 shows a comparison of tests $4 \mathrm{~S}-\mathrm{O} 2$ (molar concentrations: $0.05 \mathrm{Fe}^{2+} / 0.01 \mathrm{Cu}^{2+} / 1.5 \mathrm{Cl}^{-}$, with dissolved oxygen) and 4S-N2 (molar concentrations: $0.05 \mathrm{Fe}^{2+} / 0.01 \mathrm{Cu}^{2+} / 1.5 \mathrm{Cl}^{-}$, without dissolved oxygen), in a sulphate environment, after 400 $\mathrm{h}$ of leaching.

\subsection{Discussion}

After performing the leaching tests as described above, the influence of dissolved oxygen on the solution and of the ferrous/ cupric/ferric ions in an acidic chlorinated system can be analyzed.

\subsubsection{Effect of dissolved oxygen on acidic chlorinated solutions}

The results of dissolving copper during $400 \mathrm{~h}$, given in Table I and Fig. 1, show that in all cases, more copper dissolves in 
solutions with dissolved oxygen. Both with and without oxygen in acidic chloride media, chalcopyrite can react to form stable cuprous ion and solids (Equation 1, [10]).

$$
2 \mathrm{CuFeS}_{2}+4 \mathrm{H}^{+} \rightarrow \mathrm{Cu}_{2} \mathrm{~S}_{2}+2 \mathrm{Fe}^{2+}+2 \mathrm{H}_{2} \mathrm{~S}
$$

Reaction 1 represents a non-oxidative dissolution, documented by Nicol, et al., 2010, [10], in which covellite $\left(\mathrm{Cu}_{2} \mathrm{~S}_{2}\right)$ is formed at low solution potentials (550 mV/SHE). The partially vacant valence bonds of $\mathrm{Cu}_{2} \mathrm{~S}_{2}$ has strong contributions from the $3 p$ orbital of the sulfur, which lead to a more correct description of covellite as $\left(\mathrm{Cu}^{+}\right)_{3}\left(\mathrm{~S}^{2-}\right)\left(\mathrm{S}_{2}^{-}\right)$; the oxidation state of copper in the majority of chalcogenides is $\mathrm{Cu}^{+},[18]$.

Oxygen, in addition to being an oxidant, is a catalyst for the further oxidation of ferrous and cuprous ions on the surface of the chalcopyrite. A high concentration of dissolved oxygen usually leads to a more positive solution potential; similarly, a more acidic solution ( $\mathrm{pH}$ close to 1,0 ) also favors the oxidation of ferrous to ferric ions by the dissolved oxygen, consequently, higher potentials are found under these conditions, [19]. However, it has been found that the ferrous ion tends to prevail in highly acidic solutions, [20], and furthermore, in the present study, the difference in solution potential in solutions without and with dissolved oxygen was only $10 \mathrm{mV}$ on the average.

Therefore, the catalytic action of dissolved oxygen may be explained by an adsorption of the gas on the surface of the sulphated ore, causing polarization of the covalent bonds in the crystal lattice and forming a negatively charged superficial layer; this perhaps would attract positive ions when in contact with the solution, [21].

This effect destabilizes the structure, which in turn, increases the diffusion rate through the passivating layer; a destabilizing effect caused by the interaction of the unpaired electrons of the adsorbed oxygen with the electrons in the ore is possible. The localized weakening of the ore's structure due to the adsorption of oxygen would imply a decrease of the activation energy of the dissolving process. The catalytic action of the dissolved oxygen would be due to its high electronegativity and paramagnetism, which gives it great oxidizing power from the thermodynamic standpoint, but because of its low kinetic reactivity, the chemical oxidation reaction occurs slowly, allowing other oxidizing agents present (in this case, cupric ions coexisting with ferrous ions) to react, favoring the oxygen-ore interaction.
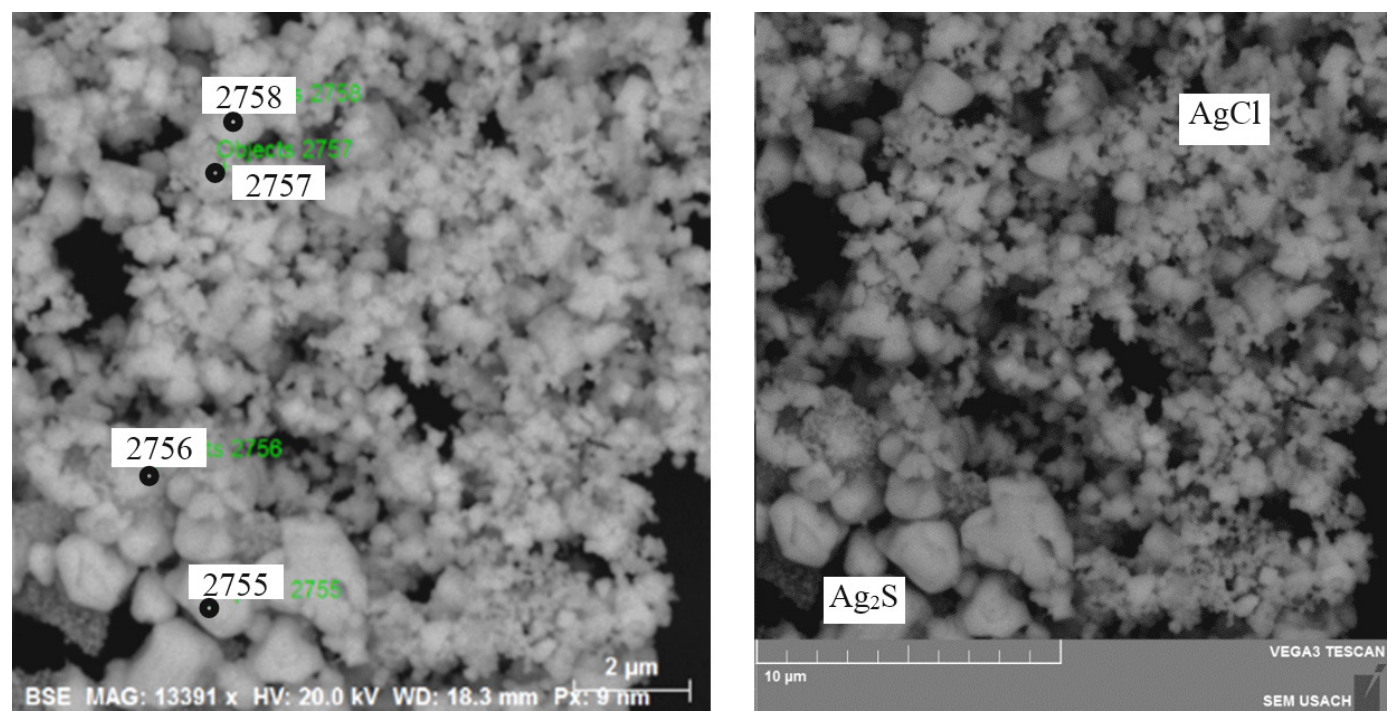

\begin{tabular}{cccc}
\hline \multicolumn{4}{c}{ Norm. mass percent (\%) } \\
\hline Spectrum & $\mathrm{S}$ & $\mathrm{Cl}$ & $\mathrm{Ag}$ \\
\hline Obj. 2755 & 0.17 & 16.54 & 83.29 \\
Obj. 2756 & 0.70 & 18.82 & 80.49 \\
Obj. 2757 & 0.06 & 16.95 & 82.99 \\
Obj. 2758 & 0.09 & 13.03 & 86.88 \\
Mean value: & 0.25 & 16.33 & 83.41 \\
Sigma: & 0.30 & 2.41 & 2.63 \\
Sigma mean: & 0.15 & 1.21 & 1.31 \\
\hline
\end{tabular}

Fig. 3: SEM micrograph of the silver nitrate solution sample sediments of test 3-O2 (molar concentrations: $0.05 \mathrm{Fe}^{2+} / 1.5 \mathrm{Cl}^{-} \mathrm{M}$ ), $\mathrm{pH} 1$, with dissolved oxygen, without addition of sulphates, after $400 \mathrm{~h}$ of shaking. 


\begin{tabular}{llcc}
\hline & X-ray diffraction & \multicolumn{2}{c}{ Fluorescence } \\
\hline Component species & \multicolumn{1}{c}{ Composition } & Element & Concentration \\
\hline Chalcopyrite & $\mathrm{CuFeS}_{2}$ & $\mathrm{O}$ & $40,2 \%$ \\
Akaganeite & $\mathrm{Fe}_{8}(\mathrm{O}, \mathrm{OH})_{16} \mathrm{Cl}_{1.3}$ & $\mathrm{Fe}$ & $28,5 \%$ \\
Iron hydroxide sulphate & $2 \mathrm{Fe}(\mathrm{OH}) \mathrm{SO}_{4}$ & $\mathrm{Cu}$ & $11,9 \%$ \\
Ramsbeckite & $\mathrm{Cu}_{15}\left(\mathrm{SO}_{4}\right)_{4}(\mathrm{OH})_{22} 6 \mathrm{H}_{2} \mathrm{O}$ & $\mathrm{S}$ & $9,2 \%$ \\
& & $\mathrm{Cl}$ & $8,9 \%$ \\
\hline
\end{tabular}
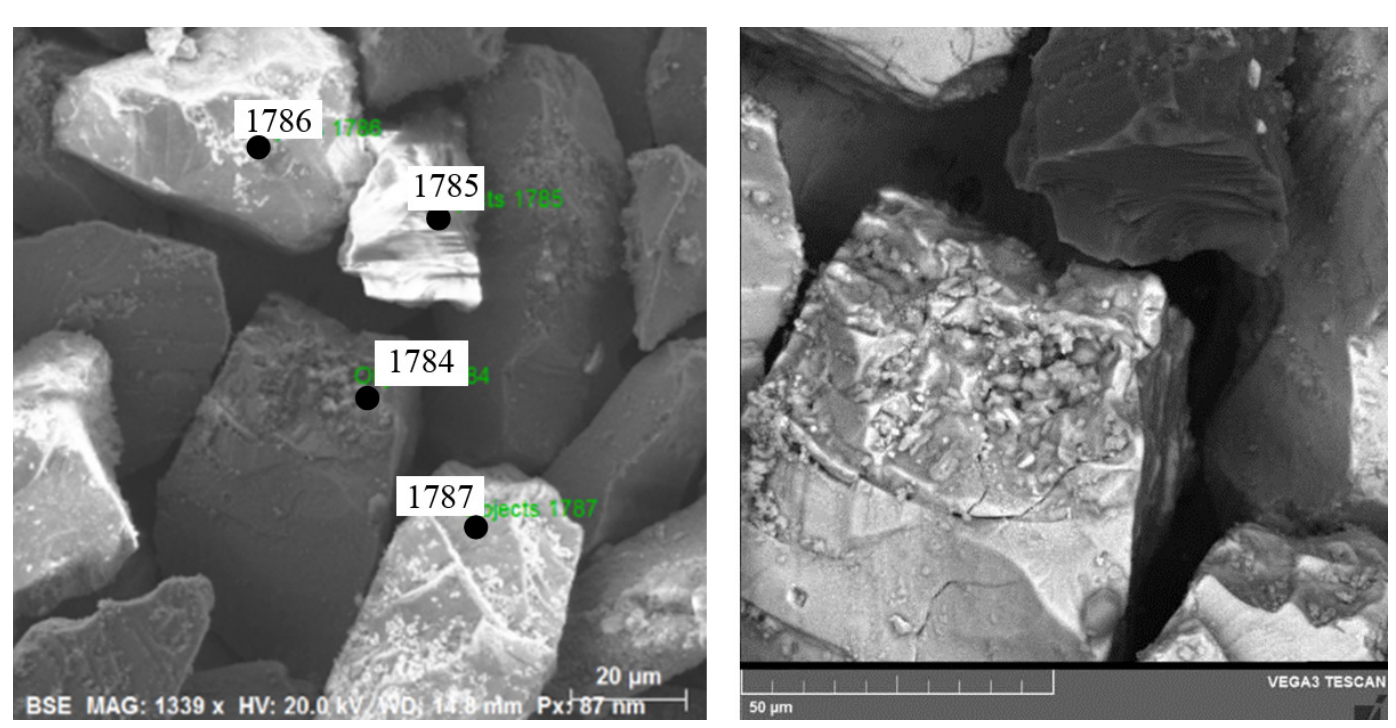

\begin{tabular}{lcccccc}
\hline \multicolumn{7}{c}{ Norm. mass percent $(\%)$} \\
\hline Spectrum & $\mathrm{Al}$ & $\mathrm{Si}$ & $\mathrm{S}$ & $\mathrm{Cl}$ & $\mathrm{Fe}$ & $\mathrm{Cu}$ \\
\hline Obj. 1784 & 0.26 & 1.32 & 30.08 & 9.2 & 45.85 & 13.3 \\
Obj. 1785 & 0.26 & 15.17 & 10.74 & 3.67 & 58.59 & 11.56 \\
Obj. 1786 & 0.40 & 0.47 & 23.08 & 15.18 & 42.98 & 17.90 \\
Obj.1787 & 0.29 & - & 27.48 & 0.57 & 36.48 & 35.18 \\
Mean value: & 0.30 & 5.65 & 22.84 & 7.15 & 45.97 & 19.49 \\
Sigma: & 0.07 & 8.25 & 8.57 & 6.43 & 9.28 & 10.80 \\
Sigma mean: & 0.03 & 4.13 & 4.29 & 3.21 & 4.64 & 5.40 \\
\hline
\end{tabular}

Fig. 4: SEM micrograph and X-ray diffraction and fluorescence of altered chalcopyrite leaching residue of test 1-O2N2 (molar concentrations: $\left.0.50 \mathrm{Fe}^{2+} / 0.01 \mathrm{Cu}^{2+} / 1.5 \mathrm{Cl}^{-} \mathrm{M}\right), \mathrm{pH} 1$, with dissolved oxygen, without added sulphates, after $400 \mathrm{~h}$ of leaching.

In the tests with dissolved oxygen there was more reaction of the ore, even though on the surface there was no detectable product layer. The explanation for this is that all of the hydrogen sulfide $\left(\mathrm{H}_{2} \mathrm{~S}\right)$ generated was carried by the air stream without the formation of a product layer, or, conversely, that the dissolved oxygen and the hydrogen sulfide react to form $\mathrm{SO}_{2}$, although this is unlikely. In the tests without dissolved oxygen there was very little reaction, as reflected in the low level of copper dissolution and in the absence of a product layer on the surface of the ore.

\subsubsection{Effect of cupric and ferrous ions in acidic solution}

The analysis of the residues from all the experiments does not show the formation of chlorine-copper species; furthermore, there is no evidence of covellite $\left(\mathrm{Cu}_{2} \mathrm{~S}_{2}\right)$ formation, as would be expected, probably because its quantity was too little to detect.

The improvement in the leaching rate of chalcopyrite at low voltages (below a critical voltage of about $550 \mathrm{mV} / \mathrm{SHE}$ ) is possible only when the ferrous and cupric ions coexist in the solution due to a synergistic effect between them, [22]. A twostage reductive/oxidative dissolving model is proposed to 


\begin{tabular}{lcccccc}
\hline \multicolumn{1}{c}{ Spectrum } & Norm. mass percent $(\%)$ & & \\
\hline Obj. 4183 & $\mathrm{O}$ & $\mathrm{Si}$ & $\mathrm{S}$ & $\mathrm{Al}$ & $\mathrm{Fe}$ & $\mathrm{Cu}$ \\
Obj. 4184 & - & - & 39.46 & - & 29.45 & 31.08 \\
Obj. 4186 & 29.17 & 21.92 & - & 0.15 & 11.38 & - \\
Obj. 4187 & 52.26 & 19.04 & - & 0.57 & 6.01 & - \\
Mean value: & - & - & 39.27 & - & 29.17 & 31.56 \\
Sigma: & 40.71 & 20.48 & 39.37 & 0.36 & 19 & 31.32 \\
Sigma mean: & 16.33 & 2.03 & 0.13 & 0.30 & 12.11 & 0.33 \\
& 8.16 & 1.02 & 0.07 & 0.15 & 6.05 & 0.17 \\
\hline
\end{tabular}
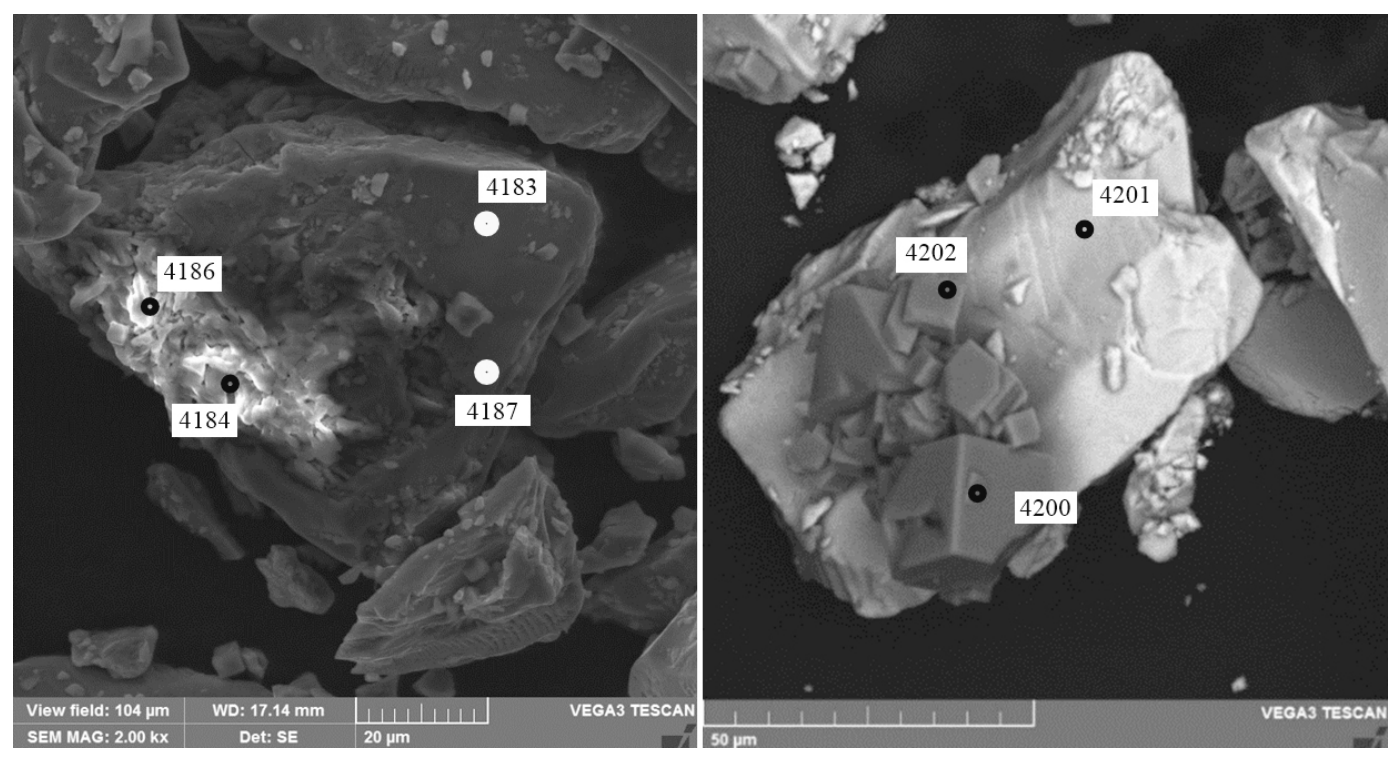

\begin{tabular}{lccccc}
\hline \multicolumn{7}{c}{ Norm. mass percent (\%) } \\
\hline Spectrum & $\mathrm{O}$ & $\mathrm{Al}$ & $\mathrm{S}$ & $\mathrm{Fe}$ & $\mathrm{Cu}$ \\
\hline Obj. 4200 & 0.96 & 0.17 & 35.28 & 30.75 & 32.84 \\
Obj. 4201 & 0.33 & - & 31.45 & 32.96 & 35.27 \\
Obj. 4202 & 0.11 & 0.18 & 30.85 & 32.79 & 36.07 \\
Mean value: & 0.46 & 0.17 & 32.53 & 32.17 & 34.73 \\
Sigma: & 0.44 & 0.01 & 2.41 & 1.23 & 1.68 \\
Sigma mean: & 0.26 & 0.01 & 1.39 & 0.71 & 0.97 \\
\hline
\end{tabular}

Fig. 5: SEM micrograph of altered chalcopyrite leaching residue of 4S-O2 and 4S-N2. Left, test 47-O2 (with dissolved oxygen); right, test 4S$\mathrm{N} 2$ (without dissolved oxygen), both with molar concentrations of $0.05 \mathrm{Fe}^{2+} / 0.01 \mathrm{Cu}^{2+} / 1.5 \mathrm{Cl}^{-}$), $\mathrm{pH} 1$, with added sulphates, $400 \mathrm{~h}$ of leaching.

explain this phenomenon, assuming the intermediate formation of chalcocite $\left(\mathrm{Cu}_{2} \mathrm{~S}\right)$ during the oxidation of the chalcopyrite, Equation 2, and the subsequent rapid oxidation of the chalcocite according to Equation 3 or Equation 4, [23].

$$
\begin{aligned}
& \mathrm{CuFeS}_{2}+3 \mathrm{Cu}^{2+}+3 \mathrm{Fe}^{2+} \rightarrow 2 \mathrm{Cu}_{2} \mathrm{~S}+4 \mathrm{Fe}^{3+} \\
& \mathrm{Cu}_{2} \mathrm{~S}+4 \mathrm{Fe}^{3+} \rightarrow 2 \mathrm{Cu}^{2+}+\mathrm{S}+4 \mathrm{Fe}^{2+} \\
& \mathrm{Cu}_{2} \mathrm{~S}+4 \mathrm{H}^{+}+\mathrm{O}_{2} \rightarrow 2 \mathrm{Cu}^{2+}+\mathrm{S}+2 \mathrm{H}_{2} \mathrm{O}
\end{aligned}
$$

The model predicts the formation of an intermediate chalcocite product, which is oxidized more easily than chalcopyrite, and this leads to the increased extraction of copper at low solution potentials, in the presence of the cupric and ferrous ions.

The presence of ferrous ions coexisting with cupric ions was beneficial to increase the dissolution kinetics of copper. The action of cupric ions in solution improves the leaching rate in a sulphate environment and the presence of ferrous ions is important for that purpose, [24]. The average increase in copper 
extraction in those experiments where ferrous and cupric ions coexist in chloride media, was $48.5 \%$.

On the surface of the chalcopyrite, the oxidation of ferrous ions by the dissolved oxygen is faster than in the liquid phase (Equation 2). The ferric ions produced on the oxidized surface of the chalcopyrite (Equation 3) are reduced simultaneously to ferrous ions. In this model, ferrous and ferric ions adsorbed on the surface of the chalcopyrite are the mediators in the transfer of electrons from the chalcopyrite to the dissolved oxygen, [23].

The effects of ferrous ions in sulfuric acid solutions with ferric ions in the absence of dissolved oxygen were studied, and it was concluded that in the presence of cupric ions, the oxidation of chalcopyrite was improved due to the high concentration of ferrous ions, [25].

It is proposed that cupric chloride is reduced much faster than ferric chloride on the surface of chalcopyrite; cuprous chloride is oxidized faster than ferrous chloride, [26]. In general, the $\mathrm{Cu}^{2+} / \mathrm{Cu}^{+}$couple is faster and more reversible than the $\mathrm{Fe}^{3+} / \mathrm{Fe}^{2+}$ couple in the corrosion of chalcopyrite, because the mixed voltage, the corrosion current, and the oxidation rate are higher in the presence of cupric ions than of ferric ions.

These improvements in the leaching rate of chalcopyrite at low voltages (below a critical voltage of around $550 \mathrm{mV} / \mathrm{SHE}$ ) are possible only when ferrous and cupric ions coexist in the solution, due to a synergistic effect between these two ions, [22].

\subsubsection{Generation de hydrogen sulfide}

It is proposed that chalcopyrite dissolution can occur in the absence of any oxidizing reagent, with the formation of cupric ions and soluble sulfur species, which presumably is $\mathrm{H}_{2} \mathrm{~S}$, [27]. Studies of the anodic dissolving of chalcopyrite in deoxygenated sulfuric acid solutions, free of ferric ions, at $\mathrm{pH} 1.7$ and 70 ${ }^{\circ} \mathrm{C}$ were performed, varying the applied voltage over the 550 to $900 \mathrm{mV} / \mathrm{SHE},[28]$. The authors concluded that for voltages below $700 \mathrm{mV} / \mathrm{SHE}$, there is an imbalance between the total electronic charge $(\mathrm{Qe})$ passed to the solution and the ionic charge $\left(\mathrm{Q}_{+}\right)$associated with the $\mathrm{Cu}^{2+}, \mathrm{Fe}^{2+}$ and $\mathrm{Fe}^{3+}$ ions released into the solution, so that $\mathrm{Qe}<\mathrm{Q}_{+}$. This imbalance of positive and negative charges indicates that during the dissolving at low potentials, there is some additional positive charge that is being incorporated to the chalcopyrite structure. These results are interpreted as a mechanism that involves a reaction with protons with the formation of an intermediate polysulfide compound. In this case chalcopyrite dissolution, can be represented by Equation 5 .

$$
\mathrm{CuFeS}_{2}+2 \mathrm{H}^{+} \rightarrow \mathrm{Cu}^{2+}+\mathrm{Fe}^{2+}+2 \mathrm{HS}^{*}+2 \mathrm{e}^{-}
$$

In this reaction the chalcopyrite is dissolved anodically as it reacts with the protons, which remove the sulfide ions from the crystal lattice of chalcopyrite, first as $\mathrm{HS}^{*}$ and later, as it continues to react with $\mathrm{H}^{+}$, in the form of $\mathrm{H}_{2} \mathrm{~S}^{*+}$, which can remain on the surface of the chalcopyrite, giving rise to a wide range of polysulfides, [29]. This passive layer can hinder the diffusion of the protons through that layer, slowing or preventing the formation of $\mathrm{H}_{2} \mathrm{~S}$.

The oxidation of chalcopyrite takes place through a progressive ore reduction leading to covellite. It is proposed that the oxidation of chalcopyrite forms a nonstoichiometric copper and iron sulfide, and the elemental sulfur is also transformed progressively from the ore, initially being released as HS* from the chalcopyrite (Equation 5), becoming the precursor of the passivating species on the solid surface. This proposal is based on the fact that in the preliminary tests with limited oxygen, without the injection of air that can carry the $\mathrm{H}_{2} \mathrm{~S}$, the small amount formed was transformed and deposited on the surface of the ore. Fig. 4 shows the SEM micrograph and the corresponding X-ray diffractogram and fluorescence of the leaching residue of experiment 1-O2N2 (molar concentrations: 0.50 $\left.\mathrm{Fe}^{2+} / 0.01 \mathrm{Cu}^{2+} / 1.5 \mathrm{Cl}^{-}\right), \mathrm{pH} 1$, with dissolved oxygen and no added sulphates, after $400 \mathrm{~h}$ of leaching. A surface with diminished amounts of sulfur and copper is observed, showing that there is more copper is dissolved and that there is a progressive transformation of the sulfur on the surface of the ore. In this media with no added sulphates, akaganeite $\left[\mathrm{Fe}_{8}(\mathrm{O}, \mathrm{OH})_{16} \mathrm{Cl}_{1.3}\right]$, iron and copper chlorides, and iron and copper sulphates are formed. It should be stressed that the associated sulphate originated from the sulfur contained in the chalcopyrite. At the beginning of the leaching experiments, the solution contained dissolved oxygen that was slowly consumed as the leaching proceeded. Since the reactors were hermetically closed in order to avoid the loss of the generated $\mathrm{H}_{2} \mathrm{~S}$, the sulfur reacted with the iron and copper in solution.

To detect the formation of hydrogen sulfide, which is reported to be the possible precursor of passivating species, [23], an indirect method of determination was used. Air was injected into the solution throughout the aerobic leaching experiments (1-O2 to 6-O2), which carried the $\mathrm{H}_{2} \mathrm{~S}$ generated into a solution of $0.05 \mathrm{M} \mathrm{AgNO}_{3}$, causing the precipitation of silver sulfide, see Figs 2 and 3, Equation 1 (reactor) and Equation 6 (sample).

$$
\mathrm{H}_{2} \mathrm{~S}+2 \mathrm{AgNO}_{3} \rightarrow \mathrm{Ag}_{2} \mathrm{~S}(\mathrm{~s})+2 \mathrm{HNO}_{3}
$$

Of all the hydrogen sulfide formed during the acidic leaching of chalcopyrite, it is assumed that part remains in the solution and the other part leaves the solution as a gas. For this reason, the implemented setup is meant to confirm, rather than quantify, the formation of hydrogen sulfide.

In the tests with dissolved oxygen (air flow), when the $\mathrm{H}_{2} \mathrm{~S}$ leaving the reactor is precipitated by the silver nitrate (equation 6) and the precipitates are analyzed, the presence of silver sulfide is confirmed (see Fig. 3). Furthermore, the solution is acidified.

As the $\mathrm{H}_{2} \mathrm{~S}$ produced is carried over, it cannot be involved in the formation of products, although the small dissolved part may cause the thin layer to be formed. It should be mentioned that the $\mathrm{H}_{2} \mathrm{~S}$ has been reported in sulphated acidic solutions at $70^{\circ} \mathrm{C},[23]$, without any certainty of whether that formation is due to the sulfur from the chalcopyrite or from the added sulphate; its formation at ambient temperature and in chlorinated 
solutions without the addition of sulphates has not been reported, as in the case of the experimental results presented in the present work.

The tests with dissolved oxygen produced a more quantitative reaction of the chalcopyrite. However, on the surface there was no detectable product layer. Although the dissolved oxygen, upon reacting with the chalcopyrite, formed hydrogen sulfide $\left(\mathrm{H}_{2} \mathrm{~S}\right)$, external factors did not allow a product layer to be formed on the solid surface, either because it was carried away by the air or due to its oxidation with the dissolved oxygen.

In an acidic chloride medium without added sulphates, in the presence of ferrous/cupric ions $\left(0.05 \mathrm{M} \mathrm{Fe}^{2+}\right.$ and $0.01 \mathrm{M}$ $\left.\mathrm{Cu}^{2+}\right)$, there is a change in the product layer formed on the surface, different from that formed in an environment with added sulphates. This probably promotes an increase in the copper dissolution kinetics of copper. The following sequence of reactions is proposed:

First, chalcopyrite reacts slowly with the hydrogen ion present in the acidic solution to form $\mathrm{H}_{2} \mathrm{~S}$ (evidenced by the image in Fig. 3), equation 1. Simultaneously, chalcopyrite interacts with cupric and ferrous ions, reducing the former and oxidizing the latter to form chalcocite (equation 2).

In the presence of ferric ion, the sulfide of chalcocite is readily oxidized by ferric ion or simply oxygen to form elemental sulfur, releasing the copper as cuprous ions.

$$
\begin{aligned}
& \mathrm{Cu}_{2} \mathrm{~S}+2 \mathrm{Fe}^{3+}+2 \mathrm{Cl}^{-} \rightarrow 2 \mathrm{CuCl}+\mathrm{S}+2 \mathrm{Fe}^{2+} \\
& 2 \mathrm{Cu}_{2} \mathrm{~S}+4 \mathrm{H}^{+}+\mathrm{O}_{2}+4 \mathrm{Cl}^{-} \rightarrow 4 \mathrm{CuCl}+2 \mathrm{~S}+2 \mathrm{H}_{2} \mathrm{O}
\end{aligned}
$$

Assuming that the reaction of Equation 1 is favored, a nonoxidative/oxidative model is proposed in which it is established that the addition of ferrous ions improves the dissolving rate when cupric ions are present. This model is similar to that proposed by Hiroyoshi et al., 2004, [22], but applied here for chloride media.

\subsubsection{Solutions with added sulphates}

The SEM micrographs of the residue selected from each experimental condition (for tests both with and without oxygen) in all the samples consisted of primarily unreacted chalcopyrite and small amounts of product layer. The exceptions are tests $4 \mathrm{~S}-\mathrm{O} 2$ (molar concentrations: $0.05 \mathrm{Fe}^{2+} / 0.01 \mathrm{Cu}^{2+} / 1.5 \mathrm{Cl}^{-}$with dissolved oxygen) and 4S-N2 (molar concentrations: 0.05 $\mathrm{Fe}^{2+} / 0.01 \mathrm{Cu}^{2+} / 1.5 \mathrm{Cl}^{-}$, without dissolved oxygen), in a sulphated environment, where a product layer on the surface of the chalcopyrite can be distinctly observed (Fig. 5). After $400 \mathrm{~h}$ of leaching, the surface of the chalcopyrite in the solution without oxygen (4S-N2), there is a nonstoichiometric formation of sulfur and chalcopyrite crystals, while the aerobic tests show the formation of jarosite (4S-O2). The amount of jarosite produced decreases when the acidity is increased in the chloride, as well as sulphate medium, [30]. Equation 9 shows a precipitation reaction typical of a jarosite. It is believed that this reaction is not reversible in systems with chalcopyrite, since it is an insoluble product, [31].

$$
\begin{aligned}
& \mathrm{Na}^{+}+3 \mathrm{Fe}^{3+}+2 \mathrm{SO}_{4}{ }^{2-}+6 \mathrm{H}_{2} \mathrm{O} \leftrightarrow \mathrm{NaFe}_{3}\left(\mathrm{SO}_{4}\right)_{2} \\
& (\mathrm{OH})_{6}+6 \mathrm{H}^{+}
\end{aligned}
$$

If the formation of jarosite causes the passivation on chalcopyrite, it can be assumed that pyrite would show a similar behavior. However, it is well known that pyrite does not undergo passivation. It can be seen that the formation of a product layer on the surface of the ore is not homogeneous, and this can be explained by the fact that on the surface of the chalcopyrite, $\mathrm{Cu}^{+} \mathrm{Fe}^{3+}\left(\mathrm{S}^{2-}\right)_{2}$, on some plane orientations, the $\mathrm{Cu}$ is being oxidized and the $\mathrm{Fe}$ is being reduced to $\mathrm{Fe}^{2+}$, while the $\mathrm{S}$ can be easily oxidized or reduced; on the surface of the ore there are $\mathrm{FeS}_{2}$ type compounds as the distances between the $\mathrm{Fe}$ and $\mathrm{Cu}$ atoms are rearranged; in other orientations there are significant changes in the atomic arrangement of $\mathrm{S}, \mathrm{Fe}$ and $\mathrm{Cu},[32]$. Another possible explanation of the nonhomogeneous formation of the product layer on the surface of the ore is its low adherence.

\section{Conclusions}

From the chlorinated acid leaching in the presence of ferrous/ cupric/ferric ions without the addition of sulphates, the following conclusions can be reached:

The presence of dissolved oxygen in an acid chloride environment is important for the leaching reaction of chalcopyrite to take place in a slightly oxidizing medium. Oxygen is a catalyst for a more quantitative oxidation of the ferrous ions on the surface of chalcopyrite, causing more release of ferrous and cuprous ions from the surface of the chalcopyrite. Therefore, there is a greater dissolution of copper in solutions with dissolved oxygen, suggesting an increase of the kinetics of the leaching process, improved the copper extraction and promotion of $\mathrm{H}_{2} \mathrm{~S}$ formation.

The presence of ferrous ions coexisting with cupric ions was beneficial to increase the dissolving kinetics of copper; the oxidation of chalcopyrite was improved due to the elevated concentrations of ferrous ions $(0.05 \mathrm{M})$, at $560 \mathrm{mV} / \mathrm{SHE}$. The extraction of copper was controlled by the ferrous/ferric concentration ratio or the redox potential of the solution. Ferrous ions suppress the oxidation of chalcopyrite when the cupric ion concentration is low.

In a chlorinated medium without the addition of sulphates with dissolved oxygen, there was generation of $\mathrm{H}_{2} \mathrm{~S}$, which is the precursor of passivating species of the surface of chalcopyrite. However, on the surface of the samples there was no detectable product layer because the hydrogen sulfide $\left(\mathrm{H}_{2} \mathrm{~S}\right)$ did not have time to form species either because it was entrained by the air stream or it reacted with the dissolved oxygen in the solution. $\mathrm{H}_{2} \mathrm{~S}$ formation at ambient temperature and in chlorinated solutions without the addition of sulphates, as in the case 
of the experimental tests of the present work, has not been previously reported.

\section{Acknowledgements}

The authors are grateful for the financial support provided for this research by the Government of Ecuador (Secretaría de Educación Superior, Ciencia, Tecnología e Innovación - SENESCYT, Instituto de Fomento al Talento Humano - IFTH) and the Universidad de Santiago de Chile (DICYT Project 051414ND).

\section{References}

1. Bonan M., Demarthe J.M., Renon H., Baratin F. Metall Trans B. 1981, 12(B), 269-274.

2. Dutrizac J.E. Metall Trans B. 1978, 9B(4), 431-439.

3. Dutrizac J.E., MacDonald R.J.C. Metall Mater Trans B. 1971, 2(8), 2310-2312.

4. Majima H., Awakura Y. Metall Trans B. 1981, 12B(1), 141-147.

5. Ballester A., Córdova E. In: Hydrocopper, 2005, 19-41.

6. Cheng C.Y., Lawson F. Hydrometallurgy. 1991, 27(3), 269-284.

7. Senanayake G. Miner Eng. 2007, 20(7)2, 634-645.

8. Antonijević M.M., Bogdanović G.D. Hydrometallurgy. 2004, 73(3-4), 245-256.

9. Lu Z.Y., Jeffrey M.I., Lawson F. Hydrometallurgy. 2000, 56(2), 145-155.

10. Nicol M., Miki H., Velásquez L. Hydrometallurgy. 2010, 103 (1-4), 86-95.

11. Skrobian M., Havlik T., Ukasik M. Hydrometallurgy. 2005, 77 (1-2), 109-114.

12. Third K.A., Cord-Ruwisch R., Watling H.R. Hydrometallurgy. 2000, 57(3), 225-233.

13. Hiroyoshi N., Hirota M., Hirajima T., Tsunekawa M. Hydrometallurgy. 1997, 47, 37-45.
14. Burkin A.R. Chemical Hydrometallurgy: Theory and Principles. Vol 1. Ed. Imperial College Press. 2001.

15. Dutrizac J.E. Metall Trans B. 1981, 12B(2), 371-378.

16. Ibañez T., Velásquez L. Rev Metal. 2013, 49(2), 131-144.

17. García D., Melgar G. Tesis: Validación del método espectrofotométrico (3500-Fe D) de la fenantrolina para determinación de hierro total en agua potable, Universidad de El Salvador. 2011.

18. Liang W., Whangbo M.H. Solid State Commun. 1993, 85(5), 405-408.

19. Velásquez L., Miki H., Nicol M. Hydrometallurgy. 2010, 103 (1-4), 80-85.

20. Acevedo, F., Gentina J. Fundamentos Y Perspectivas de Las Tecnologías Biomineras. Ed. Pontificia Universidad de Valparaíso. 2005.

21. González A. Tesis: Influencia de la acción química del oxígeno en la lixiviacion química y biológica de calcopirita a $70^{\circ} \mathrm{C}$, Universidad de Chile. 2010.

22. Hiroyoshi N., Kuroiwa S., Miki H., Tsunekawa M., Hirajima T. Hydrometallurgy. 2004, 74(1-2), 103-116.

23. Álvarez M. Tesis: Lixiviación ácida no oxidativa de calcopirita a $70^{\circ} \mathrm{C}$, Universidad de Chile. 2012.

24. Elsherief A.E. Miner Eng. 2002, 15(4), 215-223.

25. Hiroyoshi N., Miki H., Hirajima T., Tsunekawa M. Hydrometallurgy. 2001, 60(3), 185-197.

26. Parker G.K. Tesis: Spectroelectrochemical investigation of chalcopyrite leaching, Griffith University. 2005.

27. Lázaro I., Nicol M.J. J Appl Electrochem. 2006, 36(4), 425-431.

28. Jordan H., Vargas T. ECS Trans. 2010, 28(6), 201-209.

29. Jordan H., Sanhueza A., Gautier V., Escobar B., Vargas T. Hydrometallurgy. 2006, 83(1-4), 55-62.

30. Kinnunen P.H.M., Heimala S., Riekkola-Vanhanen M.L., Puhakka J.A. Bioresour Technol. 2006, 97(14), 1727-1734.

31. Leahy M.J., Schwarz M.P. Hydrometallurgy. 2009, 98(1-2), 181-191.

32. Li Y., Kawashima N., Li J., Chandra A.P., Gerson A.R. Adv Colloid Interface Sci. 2013, 197-198, 1-32. 